\title{
Real-World Evaluation of Direct and Indirect Economic Burden Among Endometriosis Patients in the United States
}

\author{
Ahmed M. Soliman · Eric Surrey • Machaon Bonafede · James K. Nelson • \\ Jane Castelli-Haley
}

Received: September 5, 2017 / Published online: February 15, 2018

(C) The Author(s) 2018. This article is an open access publication

\section{ABSTRACT}

Introduction: The prevalence of endometriosis and the need for treatment in the USA has led to the need to explore the contemporary cost burden associated with the disease. This retrospective cohort study compared direct and indirect healthcare costs in patients with endometriosis to a control group without endometriosis.

Methods: Women aged 18-49 years with endometriosis (date of initial diagnosis $=$ index date) were identified in the Truven Health

Enhanced content To view enhanced content for this article go to http://www.medengine.com/Redeem/ AF3B4F601BFBE18C.

Electronic supplementary material The online version of this article (https://doi.org/10.1007/s12325018-0667-3) contains supplementary material, which is available to authorized users.

A. M. Soliman $(\bowtie) \cdot J$. Castelli-Haley

Abbvie, Inc, North Chicago, IL, USA

e-mail: ahmed.m.soliman@abbvie.com

E. Surrey

Colorado Center for Reproductive Medicine, Lone

Tree, CO, USA

M. Bonafede

Truven Health Analytics, An IBM Company,

Cambridge, MA, USA

J. K. Nelson

Truven Health Analytics, An IBM Company, Ann

Arbor, MI, USA
MarketScan ${ }^{\circledR}$ Commercial database between 2010 and 2014 and female control patients without endometriosis were matched by age and index year. The following outcomes were compared: healthcare resource utilization (HRU) during the 12-month pre- and post-index periods (including inpatient admissions, pharmacy claims, emergency room visits, physician office visits, and obstetrics/gynecology visits), annual direct (medical and pharmacy) and indirect (absenteeism, short-term disability, and long-term disability) healthcare costs during the 12-month post-index period (in 2014 US\$). Multivariate analyses were conducted to estimate annual total direct and indirect costs, controlling for demographics, pre-index clinical characteristics, and pre-index healthcare costs.

Results: Overall, 113,506 endometriosis patients and 927,599 controls were included. Endometriosis patients had significantly higher HRU during both the pre- and post-index periods compared to controls $(p<0.0001$, all categories of HRU). Approximately two-thirds of endometriosis patients underwent an endometriosis-related surgical procedure (including laparotomy, laparoscopy, hysterectomy, oophorectomy, and other excision/ ablation procedures) in the first 12 months post-index. Mean annual total adjusted direct costs per endometriosis patient during the 12-month post-index period was over three times higher than that for a non-endometriosis control [\$16,573 (standard deviation 
$(\mathrm{SD})=\$ 21,336) \quad$ vs. $\quad \$ 4733 \quad(\mathrm{SD}=\$ 14,833)$; $p<0.005]$. On average, incremental direct and indirect 12-month costs per endometriosis patient were $\$ 10,002$ and $\$ 2132$ compared to their matched controls $(p<0.005)$.

Conclusions: Endometriosis patients incurred significantly higher direct and indirect healthcare costs than non-endometriosis patients.

Funding: AbbVie Inc.

Keywords: Administrative claims database; Endometriosis; Health economics; Women's health; Work loss

\section{INTRODUCTION}

Endometriosis is a chronic gynecological disorder characterized by the presence of endometrial-like tissue (glands and stroma) outside the uterus [1]. It is estimated that close to 200 million women worldwide will experience endometriosis [2]. Over 10 million women in the USA have endometriosis with the highest prevalence among women aged between 30 and 40 years $[3,4]$.

Current therapeutic options for managing endometriosis include pharmacological and surgical treatments $[5,6]$. While pharmacological agents (including oral contraceptives, nonsteroidal anti-inflammatory drugs, progestogens, gestrinone, and gonadotropinreleasing hormone agonists) are often used as first-line therapy for reducing pain, surgical interventions (including laparoscopic resection, laparotomy, bilateral salpingo-oophorectomy, and hysterectomy) are the mainstay of treatment for patients with advanced endometriosis, or who remain refractory to pharmacotherapy, or those with medication-related side effects $[7,8]$.

Treatment of endometriosis through pharmacotherapy and/or surgery imposes a potentially significant economic burden on the US healthcare system [9] and on society in general through work loss and reductions in the quality of life of the sufferers [10-12]. The annual healthcare cost burden in the USA associated with endometriosis was estimated to be $\$ 22$ billion in 2002 , of which $\$ 17.3$ billion was due to direct medical costs (outpatient and hospitalization) and $\$ 4.7$ billion was due to indirect costs (loss of productivity) [13]. Later, in a multicenter, prospective study, the annual societal burden of endometriosis in the USA was estimated to be $€ 49.6$ billion (equivalent to \$69.4 billion; US\$ October 2010) [14]. The same study reported that approximately two-thirds of the costs were due to lost productivity and onethird was due to direct healthcare costs. Given the prevalence of endometriosis, there is a need to estimate and update the contemporary cost burden of endometriosis in a real-world setting. The purpose of the current retrospective study was to quantify incremental direct and indirect healthcare costs in the USA among newly diagnosed endometriosis patients in the year following diagnosis compared to those without endometriosis.

\section{METHODS}

\section{Data Source}

This study used a similar study design and analytic approach of a previously published study that estimated the direct and indirect cost burden associated with undergoing an endometriosis-related surgery [15]. This retrospective database analysis used healthcare claims data from the Truven Health MarketS$\operatorname{can}^{\circledR}$ Commercial Claims and Encounters (Commercial) and the MarketScan ${ }^{\circledR}$ Health and Productivity Management (HPM) databases for the period January 1, 2009 through June 30, 2015. The commercial database contains pooled inpatient and outpatient healthcare experience, including pharmacy claims, of approximately 40 million employees and their dependents covered under a variety of health plan types in the USA. Claims-based datasets contain relatively comprehensive real-world data on healthcare with the ability to track large numbers of patients. An important limitation of such data is that it is created from a system designed for reimbursement purposes rather than for research so that, for example, there is an absence of information on medical expenses not subject to insurance reimbursement such as 
for over-the-counter medications. More specific information on the limitations of the dataset are detailed in the "Discussion".

The HPM database includes details on workplace absenteeism, short-term disability, and workers' compensation data for a subset of individuals in the commercial database. The data is provided from employer payroll systems and disability case records supplied by data contributors to the Commercial database. Information on specific causes of absences or disability are not directly coded in the database.

All database records are de-identified and were accessed with protocols compliant with US patient confidentiality requirements, including the Health Insurance Portability and Accountability Act (HIPAA) of 1996, and thus were exempted from institutional review board approval. This article does not contain any studies with human participants or animals performed by any of the authors.

\section{Study Population}

\section{Endometriosis Cohort}

Female patients (aged 18-49 years) with a diagnosis of endometriosis (International Classification of Diseases, Ninth Revision, Clinical Modification (ICD-9-CM) 617.x) on a non-diagnostic medical claim between January 1, 2010 and June 30, 2014 during the study time frame were initially selected for analysis. The date of first diagnosis was defined as the index date. Additionally, patients were considered eligible for inclusion if they had continuous health plan coverage for 12 months before (pre-index period) and 12 months after (follow-up period) the index date. Patients with a diagnosis of endometriosis (ICD-9-CM 617.x) in any position on a non-diagnostic medical claim preceding the index date, or diagnosis of malignant neoplasm of female genitourinary organs (ICD9-CM: 179.x-184.x) or radical hysterectomy during the 12-month pre-index period were excluded. ICD-9-CM codes are used here and throughout for identifying diagnostic information because it was the required coding system during the relevant time period on insurance reimbursement claims used in the commercial database.

\section{Non-Endometriosis Control Cohort}

Patients in the non-endometriosis cohort were identified using selection criteria similar to the endometriosis cohort. Female patients with no diagnosis of endometriosis during the entire study period (January 1, 2009 through June 30, 2015) were randomly selected and directly matched 10:1 to endometriosis patients on the basis of data availability in the index year and age at index). Index date for the control cohort was randomly assigned during this time period with a date distribution matching the date distribution found among endometriosis patients.

\section{Outcome Measures}

Healthcare resource utilization and costs (allcause and endometriosis-related) were evaluated for the 12-month pre- and post-index periods. The direct healthcare costs incurred were assessed for healthcare services across various care settings: inpatient, emergency room (ER), outpatient services including obstetrician-gynecologist (OB/GYN) visits, and outpatient prescriptions. Endometriosis-related utilization and expenditures were defined as (a) medical claims with a principal diagnosis of endometriosis, (b) pharmacy claims for drugs used to treat and manage endometriosis (leuprolide, danazol, depot medroxyprogesterone, oral medroxyprogesterone acetate, levonorgestrel implants and intrauterine devices, megestrol acetate, progestin-only oral contraceptive pills, histrelin, goserelin, nafarelin, triptorelin, ganirelix, degarelix, cetrorelix, abarelix, and other oral contraceptive pills), and (c) endometriosis-related surgeries (number and proportion of patients with at least one endometriosis-related surgery overall, and stratified by laparotomy, laparoscopy, hysterectomy, oophorectomy, and other excision/ablation procedures). All expenditures were inflation adjusted to 2014 US\$ using the Medical Care component of the Bureau of Labor Statistics Consumer Price Index [16]. 
Work losses associated with absenteeism (the number of days absent from work), short-term disability (STD), and long-term disability (LTD) in the 12-month post-index period were assessed for both endometriosis and non-endometriosis cohorts in terms of the proportion of patients with each category of work loss as well as average number of days lost. To assess indirect costs due to work loss, a daily wage was calculated using the age-, gender-, and geographic region-adjusted wage rate from the US Bureau of Labor Statistics from the year 2010. An estimated daily wage rate (\$240 per day) was considered for calculating costs from lost productivity due to STD/LTD. As STD/LTD benefit typically does not replace full wages, $70 \%$ of wages, which approximates the proportion of total wages and benefits paid by employers in the HPM database, was used.

\section{Patient Characteristics}

Patient characteristics including age, geographic region (US Census division), urbanicity, health plan type, and index year were measured on the index date. In addition, the Deyo Charlson Comorbidity Index (DCI), comorbid conditions (based on the presence of ICD-9-CM diagnosis), and medication use (based on Healthcare Common Procedure Coding System (HCPCS) and National Drug Code (NDC) codes) were measured during the 12-month pre-index period.

\section{Statistical Analysis}

Patient characteristics, healthcare utilization, and costs for each study cohort were analyzed descriptively. Continuous measures were summarized as means and standard deviations, and categorical measures were summarized as counts and percentages. Testing for statistical differences in the study outcomes between cohorts was performed using Chi square test for categorical measures, and ANOVA and $t$ tests for continuous measures.

The "real-world" costs as determined from the Commercial and HPM databases are presented first. However, the reported cost differences for the cohorts may be influenced by differences in their baseline characteristic, so adjusted cost estimates were also computed. Multivariate analysis was used to compare both direct and indirect (absence, STD, LTD, and total) cost outcomes in patients with and without endometriosis. Generalized linear models (GLMs) were used to estimate incremental costs for patients with endometriosis versus those without. The models used generalized estimating equations to account for within-patient correlation and used a gamma distributed error and log link to account for the distributional characteristics of cost data. Estimation of the standard error of the marginal cost was conducted by using the delta method. Two-part models were used for potentially infrequent outcomes and associated costs such as total STD costs [17]. All models controlled for the relevant patient characteristics (age, gender, geographic region, and health plan type, DCI, and baseline comorbidities) between the two cohorts. The recycled prediction method was used to estimate the marginal or incremental costs associated with endometriosis. A $p$ value of less than 0.05 was considered statistically significant.

\section{RESULTS}

\section{Study Sample}

A total of 434,809 women with endometriosis between January 1, 2010 and June 30, 2014 were initially identified, and were directly matched on age and index year in a 1:10 ratio to controls $(N=4,348,090)$ without endometriosis. Following application of all eligibility criteria (Fig. 1), a total of 113,506 women with endometriosis and 927,599 controls were included in the analysis.

\section{Patient Characteristics}

Patient characteristics are presented in Table 1. Patients with and without endometriosis were demographically similar. Endometriosis patients had a greater comorbid burden than 


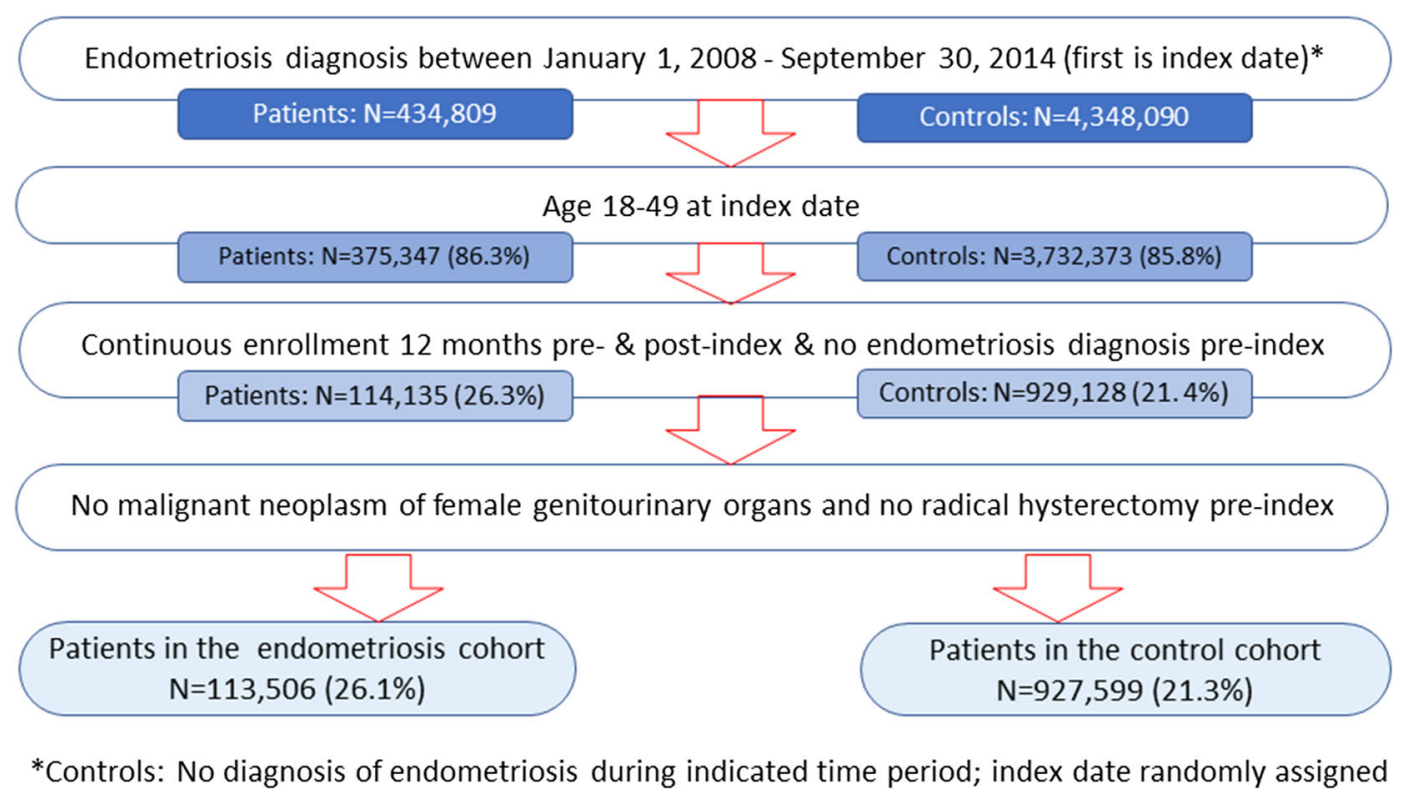

Fig. 1 Sample selection. The effect of applying eligibility criteria to population sample size is shown

demographically matched controls, as evidenced by significantly higher mean [standard deviation (SD)] CCI score for endometriosis patients in the pre-index period $[0.21(0.64)$ vs. 0.16 (0.57); $p<0.0001]$. Endometriosis patients also had significantly higher rates of all the assessed comorbidities, with gynecological comorbidities being especially common in the 12 months prior to an endometriosis diagnosis. Compared to controls, the endometriosis cohort had a higher proportion of patients with prescriptions claims for opioids, nonsteroidal anti-inflammatory drugs (NSAIDs), antidepressants, and hormonal contraceptives (all $p<0.0001)$.

\section{Healthcare Utilization and Expenditures}

Patients with endometriosis had a significantly higher rate of healthcare utilization compared to their matched controls during both the preand post-index periods (Table 2, Fig. 2). During the 12-month post-index period, $29 \%$ of patients in the endometriosis cohort reported an all-cause hospital admission compared to 6\% in the control cohort $(p<0.0001)$. More endometriosis patients than controls had an ER visit, physician office visit, and $\mathrm{OB} / \mathrm{GYN}$ visit in both the pre- and post-index periods (all $p<0.0001$ ), as well as higher average numbers of all-cause hospital admissions (post-index only), ER visits (pre- and post-index), and OB/ GYN visits (pre- and post-index) compared to their matched controls.

Endometriosis patients also showed similarly increased utilization in the 12 months prior to the index date as well as post-index, showing a greater proportion of patients with ER visits, physician office visits, and OB/GYN visits (Fig. 2).

Nearly two-thirds of the patients with endometriosis underwent an endometriosis-related surgical procedure (including hysterectomy, oophorectomy, laparoscopy, laparotomy, and other excision or ablation) compared to $1.0 \%$ in the controls, among which hysterectomy was the most common (38\%) during the 12 -month post-index period. Less than a third of endometriosis patients filled relevant therapeutic endometriosis-related prescriptions during the post-index period compared to $21 \%$ of patients in the control cohort (Table 2).

Overall, endometriosis patients incurred significantly higher annual all-cause expenditure compared to the controls during both pre- and post-index periods (Table 2, Fig. 3). Notably, the majority $(62 \%)$ of the annual costs for 
Table 1 Demographic characteristics (on index date) and clinical characteristics (during pre-index period)

\begin{tabular}{|c|c|c|c|}
\hline Patient characteristic & $\begin{array}{l}\text { Endometriosis patients } \\
(N=113,506)\end{array}$ & $\begin{array}{l}\text { Controls } \\
(N=927,599)\end{array}$ & $p$ value \\
\hline Age, mean (SD) & $37.9(7.4)$ & $38.2(7.5)$ & $<0.0001$ \\
\hline Age group, $N(\%)$ & & & $<0.0001$ \\
\hline $18-2$ & $7032(6 \%)$ & $58,619(6 \%)$ & \\
\hline $25-29$ & $9290(8 \%)$ & $65,369(7 \%)$ & \\
\hline $30-34$ & $18,615(16 \%)$ & $144,156(16 \%)$ & \\
\hline $35-39$ & $24,826(22 \%)$ & $201,881(22 \%)$ & \\
\hline $40-44$ & $28,939(25 \%)$ & $242,468(26 \%)$ & \\
\hline $45-49$ & $24,804(22 \%)$ & $215,106(23 \%)$ & \\
\hline Population density, $N(\%)$ & & & $<0.0001$ \\
\hline Urban & $94,243(83 \%)$ & $793,610(86 \%)$ & \\
\hline Rural & $17,908(16 \%)$ & $121,950(13 \%)$ & \\
\hline Unknown & $1355(1 \%)$ & $12,039(1 \%)$ & \\
\hline Geographic region, $N(\%)$ & & & $<0.0001$ \\
\hline Northeast & $18,299(16 \%)$ & $169,818(18 \%)$ & \\
\hline North central & $25,764(23 \%)$ & $206,305(22 \%)$ & \\
\hline South & $47,074(41 \%)$ & $355,934(38 \%)$ & \\
\hline West & $20,931(18 \%)$ & $182,997(20 \%)$ & \\
\hline Unknown & $1438(1 \%)$ & $12,545(1 \%)$ & \\
\hline Health plan type $(N, \%)$ & & & $<0.0001$ \\
\hline Comprehensive & $1131(1 \%)$ & $8732(1 \%)$ & \\
\hline EPO & $1638(1 \%)$ & $14,779(2 \%)$ & \\
\hline $\mathrm{HMO}$ & $16,234(14 \%)$ & $141,636(15 \%)$ & \\
\hline POS & $8508(7 \%)$ & $65,224(7 \%)$ & \\
\hline $\mathrm{PPO}$ & $67,723(60 \%)$ & $538,520(58 \%)$ & \\
\hline POS with capitation & $630(1 \%)$ & $5093(1 \%)$ & \\
\hline CDHP & $7674(7 \%)$ & $63,097(7 \%)$ & \\
\hline HDHP & $4116(4 \%)$ & $40,811(4 \%)$ & \\
\hline Unknown & $5852(5 \%)$ & $49,707(5 \%)$ & \\
\hline Deyo CCI, mean (SD) & $0.21(0.6)$ & $0.16(0.6)$ & $<0.0001$ \\
\hline \multicolumn{4}{|l|}{ Comorbid conditions, $N(\%)$} \\
\hline Upper respiratory infections & $35,478(31 \%)$ & $220,514(24 \%)$ & $<0.0001$ \\
\hline Abdominal/pelvic pain & $29,018(26 \%)$ & $65,630(7 \%)$ & $<0.0001$ \\
\hline
\end{tabular}


Table 1 continued

\begin{tabular}{|c|c|c|c|}
\hline Patient characteristic & $\begin{array}{l}\text { Endometriosis patients } \\
(N=113,506)\end{array}$ & $\begin{array}{l}\text { Controls } \\
(N=927,599)\end{array}$ & $p$ value \\
\hline Hypertension & $12,640(11 \%)$ & $79,943(9 \%)$ & $<0.0001$ \\
\hline Anxiety & $10,825(10 \%)$ & $56,401(6 \%)$ & $<0.0001$ \\
\hline Depression & $11,745(10 \%)$ & $65,587(7 \%)$ & $<0.0001$ \\
\hline Migraine & $8511(7 \%)$ & $36,980(4 \%)$ & $<0.0001$ \\
\hline Asthma & $6547(6 \%)$ & $37,170(4 \%)$ & $<0.0001$ \\
\hline Hyperlipidemia & $6543(6 \%)$ & $43,726(5 \%)$ & $<0.0001$ \\
\hline COPD & $3026(3 \%)$ & $17,613(2 \%)$ & $<0.0001$ \\
\hline Diabetes & $3927(3 \%)$ & $29,682(3 \%)$ & $<0.0001$ \\
\hline Irritable bowel syndrome & $2741(2 \%)$ & $7998(1 \%)$ & $<0.0001$ \\
\hline Osteoarthritis & $2650(2 \%)$ & $16,886(2 \%)$ & $<0.0001$ \\
\hline Acute coronary syndrome & $898(1 \%)$ & $4775(1 \%)$ & $<0.0001$ \\
\hline Pelvic peritoneal adhesions & $1647(1 \%)$ & $1821(<1 \%)$ & $<0.0001$ \\
\hline Anal or rectal pain & $484(<1 \%)$ & $1600(<1 \%)$ & $<0.0001$ \\
\hline Bladder pain & $223(<1 \%)$ & $586(<1 \%)$ & $<0.0001$ \\
\hline Heart failure & $185(<1 \%)$ & $1441(<1 \%)$ & 0.54 \\
\hline Osteoporosis & $179(<1 \%)$ & $1528(<1 \%)$ & 0.58 \\
\hline \multicolumn{4}{|l|}{ Gynecological comorbidities, $N(\%)$} \\
\hline Any gynecological comorbidity listed below & $74,053(65 \%)$ & $109,165(12 \%)$ & $<0.0001$ \\
\hline $\begin{array}{l}\text { Unspecified symptoms of female genital } \\
\text { organs }\end{array}$ & $30,057(26 \%)$ & $24,033(3 \%)$ & $<0.0001$ \\
\hline Excessive or frequent menstruation & $25,414(22 \%)$ & $28,607(3 \%)$ & $<0.0001$ \\
\hline Ovarian cysts & $20,400(18 \%)$ & $16,864(2 \%)$ & $<0.0001$ \\
\hline Uterine fibroids & $18,618(16 \%)$ & $17,571(2 \%)$ & $<0.0001$ \\
\hline Dysmenorrhea & $15,540(14 \%)$ & $11,086(1 \%)$ & $<0.0001$ \\
\hline Vaginitis & $8477(7 \%)$ & $36,065(4 \%)$ & $<0.0001$ \\
\hline Dyspareunia & $4233(4 \%)$ & $3299(0 \%)$ & $<0.0001$ \\
\hline Metrorrhagia & $4053(4 \%)$ & $5478(1 \%)$ & $<0.0001$ \\
\hline \multicolumn{4}{|l|}{ Reproductive claims, $N(\%)$} \\
\hline Pregnancy/delivery & $6513(6 \%)$ & $65,332(7 \%)$ & $<0.0001$ \\
\hline Infertility & $6127(5 \%)$ & $9077(1 \%)$ & $<0.0001$ \\
\hline Fertility treatments & $5462(5 \%)$ & $11,076(1 \%)$ & $<0.0001$ \\
\hline
\end{tabular}


Table 1 continued

\begin{tabular}{llll}
\hline Patient characteristic & $\begin{array}{l}\text { Endometriosis patients } \\
(\boldsymbol{N}=\mathbf{1 1 3}, \mathbf{5 0 6})\end{array}$ & $\begin{array}{l}\text { Controls } \\
(\boldsymbol{N = 9 2 7 , 5 9 9 )})\end{array}$ & $\boldsymbol{p}$ value \\
\hline Medications, $N(\%)$ & & & \\
Opioids & $101,557(89 \%)$ & $573,082(62 \%)$ & $<0.0001$ \\
NSAIDS & $84,498(74 \%)$ & $468,703(51 \%)$ & $<0.0001$ \\
Antidepressants & $54,055(48 \%)$ & $309,289(33 \%)$ & $<0.0001$ \\
Estrogen/progestin oral contraceptives & $51,060(45 \%)$ & $319,839(34 \%)$ & $<0.0001$ \\
\hline
\end{tabular}

CCI Charlson comorbidity index, CDHP consumer driven health plan, COPD chronic obstructive pulmonary disease, $E P O$ exclusive provider organization, $H D H P$ high deductible health plan, HMO health maintenance organization, NSAIDS nonsteroidal anti-inflammatory drugs, $P O S$ point of service, $P P O$ preferred provider organization, $S D$ standard deviation

endometriosis patients were incurred within 3 months post-index. In the 12 -month post-index period, the endometriosis-related expenditures accounted for about $39 \%$ and $1 \%$ of the total healthcare expenditures in the endometriosis and control cohorts, respectively (Fig. 4). The "endometriosis-related" expenditures among controls arose from prescriptions for drugs listed in the "Methods" section as "endometriosis-related", but many of which also have non-endometriosis indications. Healthcare and pharmacy costs tend to increase with the age of the patient, with older endometriosis patients (age 40-49) having $\$ 3171$ more in mean costs compared to younger patients (age 18-29), whereas the difference among controls was $\$ 1471$ (Table 3). Here and throughout the "Results" sections, all costs are presented in 2014 US\$.

\section{Work Loss and Indirect Costs}

Work loss was higher in the endometriosis cohort (Table 2), particularly in terms of days of absence and STD. Rates of LTD claims were low in both cohorts (although significantly higher in the endometriosis cohort both in terms of proportion of patients with a claim and total number of LTD days). This resulted in higher mean indirect cost estimates among endometriosis patients vs. controls for all categories of work loss: $\$ 5383$ vs. $\$ 4224$ per patient for the cost of absenteeism, $(p<0.0001), \$ 1709$ vs. $\$ 402$ per patient for the cost of STD $(p<0.0001)$, and $\$ 54$ vs. $\$ 26$ per patient for the cost of LTD.

\section{Adjusted Direct and Indirect Healthcare Expenditures}

Cost estimates have been presented which describe what is found in the real-world data. Additionally, multivariate analysis, detailed in the "Methods" section, provided cost estimates adjusted for baseline patient characteristics which may have differed between the cohorts. Overall, patients with endometriosis showed a significant incremental burden when compared to those without endometriosis. The mean annual incremental direct healthcare cost of endometriosis was estimated at $\$ 10,002$, while the mean incremental indirect costs related to absence hours and STD compared to non-endometriosis controls were $\$ 903$ and $\$ 1228$, respectively, (all $p<0.005$; Table 4 ). Please see Tables S1-S5 in the supplementary material for additional details on the multivariate results.

\section{DISCUSSION}

This retrospective study estimated the incremental direct and indirect costs associated with endometriosis among commercially insured 
Table 2 Utilization and costs during 12-month post-index period

\begin{tabular}{|c|c|c|c|}
\hline Outcome & $\begin{array}{l}\text { Endometriosis patients } \\
(N=113,506)\end{array}$ & $\begin{array}{l}\text { Controls } \\
(N=927,599)\end{array}$ & $p$ value \\
\hline \multicolumn{4}{|l|}{ Healthcare utilization (all-cause) } \\
\hline Patients with inpatient admission, $N(\%)$ & $33,235(29 \%)$ & $60,052(6 \%)$ & $<0.0001$ \\
\hline Admissions per patient, mean (SD) & $0.34(0.62)$ & $0.08(0.33)$ & $<0.0001$ \\
\hline Patients with emergency room visit, $N(\%)$ & $35,944(32 \%)$ & $168,471(18 \%)$ & $<0.0001$ \\
\hline ER visits per patient, mean $(\mathrm{SD})$ & $0.63(1.62)$ & $0.28(0.87)$ & $<0.0001$ \\
\hline Patients with physician office visit, $N(\%)$ & $109,835(97 \%)$ & $804,959(87 \%)$ & $<0.0001$ \\
\hline Physician office visits per patient, mean (SD) & $8.0(7.2)$ & $4.6(5.2)$ & $<0.0001$ \\
\hline Patients with $\mathrm{OB} / \mathrm{GYN}$ specialist visit, $N(\%)$ & $71,846(63 \%)$ & $341,295(37 \%)$ & $<0.0001$ \\
\hline $\mathrm{OB} / \mathrm{GYN}$ office visits per patient, mean (SD) & $1.8(2.7)$ & $0.62(1.2)$ & $<0.0001$ \\
\hline $\begin{array}{l}\text { Patients with outpatient prescription claim, } \\
N(\%)\end{array}$ & $108,828(96 \%)$ & $766,720(83 \%)$ & $<0.0001$ \\
\hline Prescriptions per patient, mean (SD) & $20.2(20.7)$ & $12.0(16.0)$ & $<0.0001$ \\
\hline \multicolumn{4}{|l|}{ Healthcare utilization (endometriosis-related) } \\
\hline Patients with inpatient admission, $N(\%)$ & $18,495(16 \%)$ & 0.0 & $<0.0001$ \\
\hline Admissions per patient, mean (SD) & $0.17(0.38)$ & 0.0 & $<0.0001$ \\
\hline Patients with emergency room visit, $N(\%)$ & $4599(4 \%)$ & 0.0 & $<0.0001$ \\
\hline ER visits per patient, mean $(\mathrm{SD})$ & $0.05(0.25)$ & 0.0 & $<0.0001$ \\
\hline Patients with physician office visit, $N(\%)$ & $51,133(45 \%)$ & 0.0 & $<0.0001$ \\
\hline Physician office visits per patient, mean (SD) & $0.79(1.35)$ & 0.0 & $<0.0001$ \\
\hline Patients with $\mathrm{OB} / \mathrm{GYN}$ specialist visit, $N(\%)$ & $34,966(31 \%)$ & 0.0 & $<0.0001$ \\
\hline $\mathrm{OB} / \mathrm{GYN}$ office visits per patient, mean (SD) & $0.49(0.99)$ & 0.0 & $<0.0001$ \\
\hline $\begin{array}{l}\text { Patients with outpatient prescription claim, } \\
N(\%)\end{array}$ & $34,008(30 \%)$ & $199,287(21 \%)$ & $<0.0001$ \\
\hline Prescriptions per patient, mean (SD) & $1.5(3.2)$ & $1.3(3.2)$ & $<0.0001$ \\
\hline $\begin{array}{l}\text { Patients with endometriosis-related surgery, } \\
N(\%)\end{array}$ & $75,935(66.9 \%)$ & $10,735(1.2 \%)$ & $<0.0001$ \\
\hline Laparotomy & $3758(3.3 \%)$ & $797(0.1 \%)$ & $<0.0001$ \\
\hline Laparoscopy & $37,238(32.8 \%)$ & $4766(0.5 \%)$ & $<0.0001$ \\
\hline Hysterectomy & $43,030(37.9 \%)$ & $5575(0.6 \%)$ & $<0.0001$ \\
\hline Hysterectomy w/same-day oophorectomy & $2206(1.9 \%)$ & $195(0.0 \%)$ & $<0.0001$ \\
\hline Oophorectomy & $4050(3.6 \%)$ & $484(0.1 \%)$ & $<0.0001$ \\
\hline Other excision/ablation & $571(0.5 \%)$ & $86(0.0 \%)$ & $<0.0001$ \\
\hline
\end{tabular}


Table 2 continued

\begin{tabular}{|c|c|c|c|}
\hline Outcome & $\begin{array}{l}\text { Endometriosis patients } \\
(N=113,506)\end{array}$ & $\begin{array}{l}\text { Controls } \\
(N=927,599)\end{array}$ & $p$ value \\
\hline \multicolumn{4}{|l|}{ Healthcare costs } \\
\hline All-cause, mean (SD) & $\$ 16,573(21,336)$ & $\$ 4733(14,833)$ & $<0.0001$ \\
\hline In terms of per patient per month (SD) & $\$ 1381(1778)$ & $\$ 394(1236)$ & $<0.0001$ \\
\hline All-cause pharmacy costs, mean (SD) & $\$ 1784(4696)$ & $\$ 1070(3910)$ & $<0.0001$ \\
\hline Endometriosis-related, mean (SD) & $\$ 6498(9046)$ & $\$ 89(497)$ & $<0.0001$ \\
\hline $\begin{array}{l}\text { Endometriosis-related pharmacy costs, mean } \\
\text { (SD) }\end{array}$ & $\$ 212(800)$ & $\$ 89(497)$ & $<0.0001$ \\
\hline \multicolumn{4}{|l|}{ Work loss } \\
\hline Patients with absence data, $N$ & 1365 & 10,051 & \\
\hline Patients with absence claim, $N(\%)$ & $955(70.0 \%)$ & $6782(67.5 \%)$ & 0.065 \\
\hline Absence days, mean (SD) & $31.1(20.9)$ & $24.3(18.7)$ & $<0.0001$ \\
\hline $\begin{array}{l}\text { Patients with short-term disability (STD) } \\
\text { data, } N\end{array}$ & 9701 & 78,266 & \\
\hline Patients with STD claim, $N(\%)$ & $3464(35.7 \%)$ & $5756(7.4 \%)$ & $<0.0001$ \\
\hline STD days, mean (SD) & $14.3(25.1)$ & $3.3(16.6)$ & $<0.0001$ \\
\hline $\begin{array}{l}\text { Patients with long-term disability (LTD) data, } \\
N\end{array}$ & 8833 & 68,271 & \\
\hline Patients with LTD claim, $N(\%)$ & $42(0.5)$ & $149(0.2)$ & $<0.0001$ \\
\hline LTD days, mean (SD) & $0.4(8.8)$ & $0.2(6.2)$ & 0.0036 \\
\hline \multicolumn{4}{|l|}{ Indirect costs due to work loss } \\
\hline Absence, mean (SD) & $\$ 5383(\$ 3807)$ & $\$ 4224(\$ 3352)$ & $<0.0001$ \\
\hline Short-term disability, mean (SD) & $\$ 1709(\$ 3057)$ & $\$ 402(\$ 2064)$ & $<0.0001$ \\
\hline Long-term disability, mean (SD) & $\$ 54(\$ 1107)$ & $\$ 26(\$ 770)$ & 0.0035 \\
\hline
\end{tabular}

All costs are estimated as per 2014 US\$

$O B / G Y N$ obstetrician or gynecologist, $S D$ standard deviation

patients in the USA and showed that the direct healthcare costs for endometriosis patients measured both 12 months prior to and after endometriosis diagnosis were significantly higher than those in matched controls. Additionally, costs due to work loss through absenteeism, STD, and LTD were also higher in patients with endometriosis. To our knowledge, this is the first major study that compared both direct and indirect healthcare costs between patients with and without endometriosis.

Analogous to the findings of previous studies $[9,13,14]$ this study showed that endometriosis patients incurred significantly higher healthcare costs compared to controls. The incremental costs per patient in the first year post- 


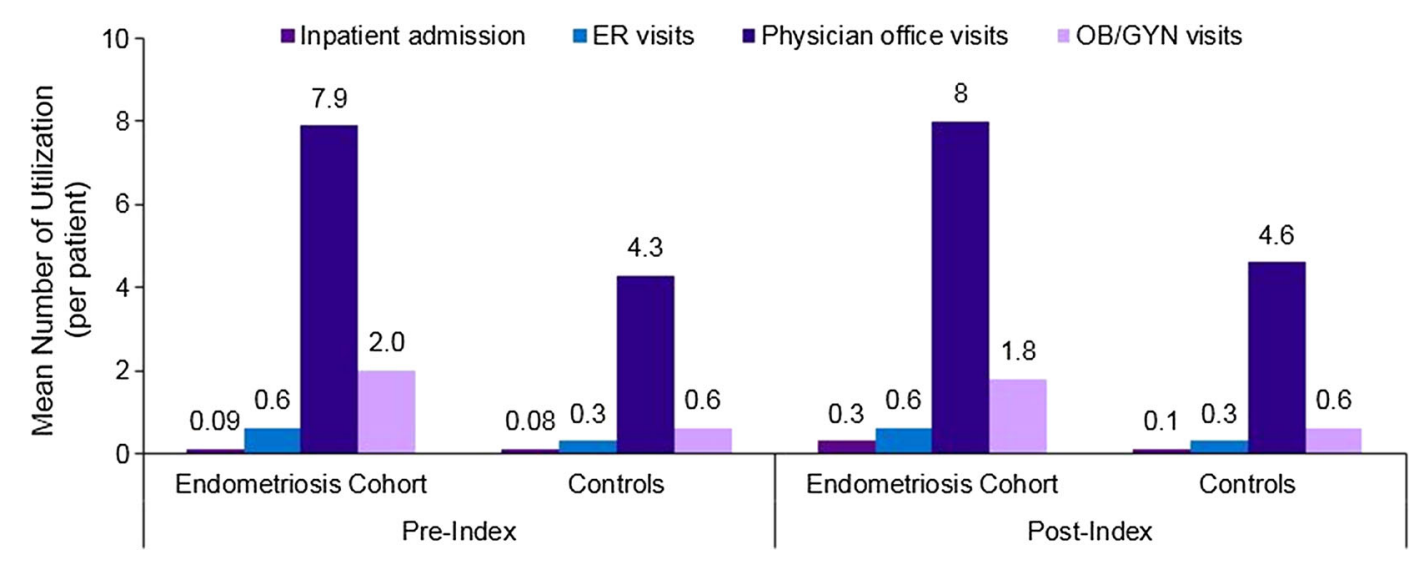

Fig. 2 All-cause healthcare utilization in the 12-month pre- and post-index periods. All endometriosis vs. control differences in utilizations in the pre-index periods and in the post-index period are significant $(p<0.0001)$

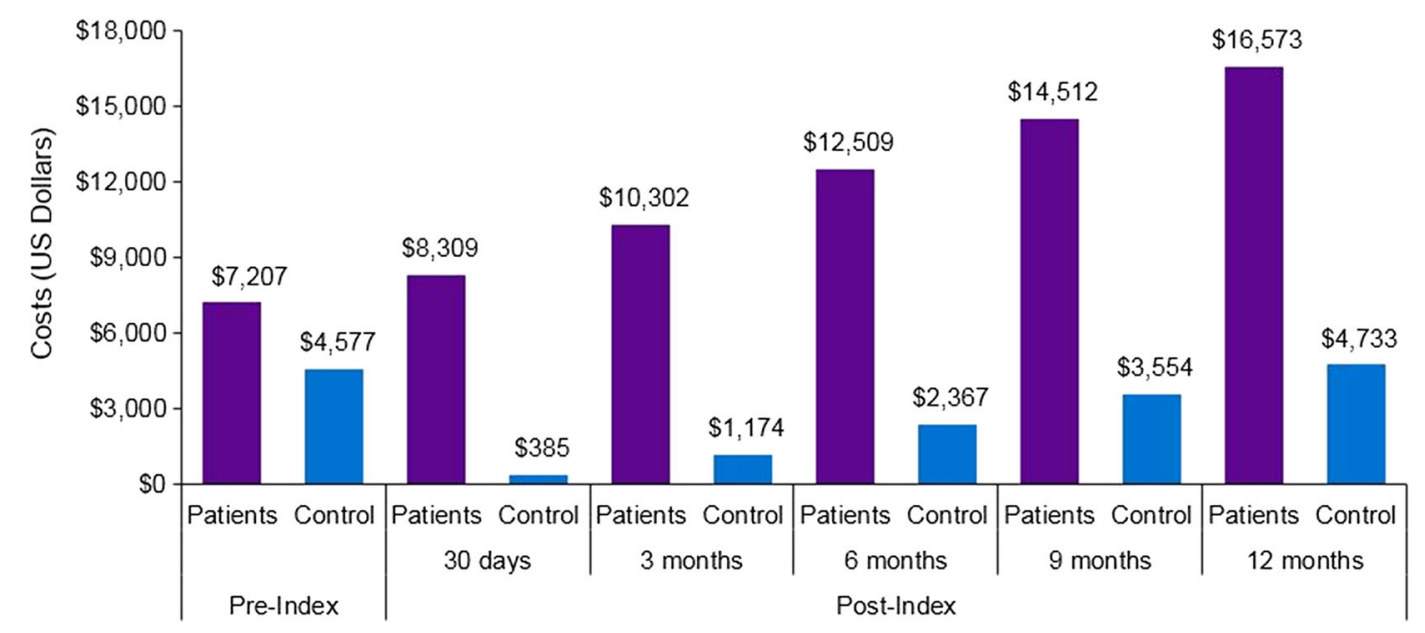

Fig. 3 All-cause healthcare costs during 12-month pre- and post-index follow-up period. Values in each time period are cumulative cost since index

diagnosis (over $\$ 10,000$ with multivariable adjustment) are substantial compared to estimates for other common gynecological ailments such as uterine fibroids (\$6873 in 2014 US\$ [18]) or menorrhagia (\$2878 in 2014 US\$ [19]). Notably, over $60 \%$ of the total annual healthcare costs for endometriosis patients were accrued within 3 months of the index date, thereby adding to the existing body of literature which has reported highest healthcare resource utilization and costs in the first year after endometriosis diagnosis [20-22].

Indirect costs associated with endometriosis are substantial as well, with average incremental indirect costs estimated at US \$2132 per patient (adjusted estimate) in the 12 months following the index diagnosis. A point to notice here is that claims data can only capture indirect losses due to the absenteeism component; data on presenteeism (reduced productivity due to illness while on the job) was not available. Estimates from a study of European Union countries suggest that indirect costs due to presenteeism can substantially exceed the costs of absenteeism, by a factor of 2: $€ 6298$ due to presenteeism vs. $€ 3280$ due to absenteeism [14]. A study of 10 countries across multiple continents estimated that endometriosis resulted in the equivalent work loss of $6.4 \mathrm{~h} /$ week due to presenteeism and $4.4 \mathrm{~h} /$ week due to 


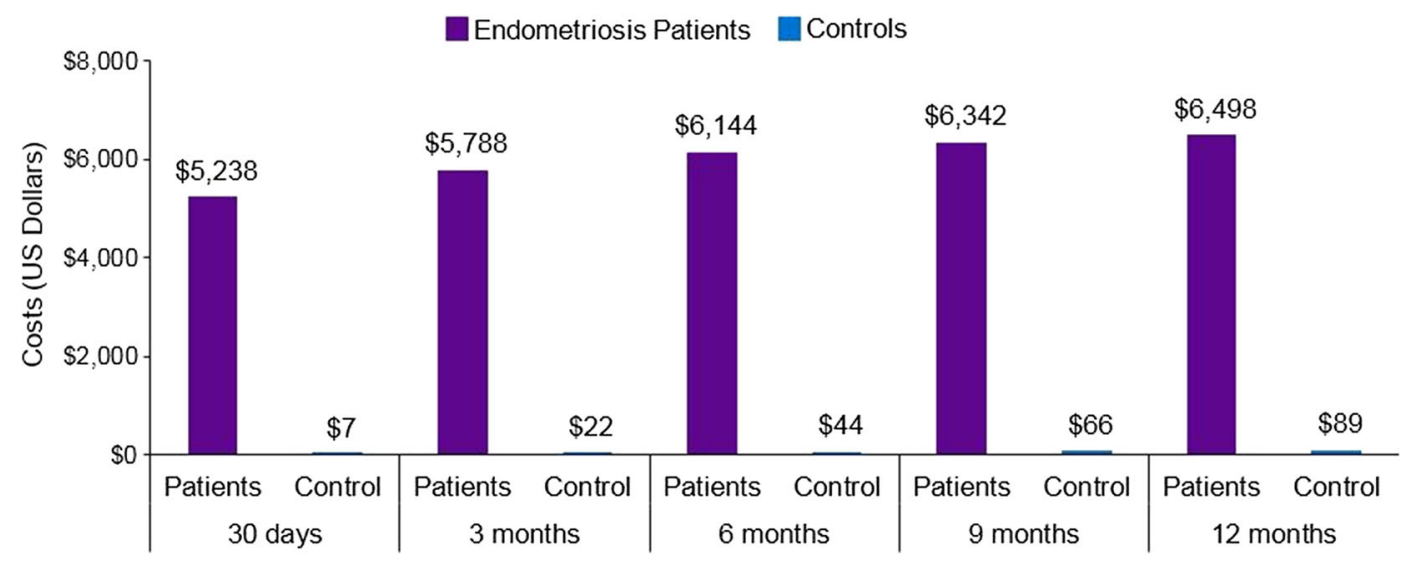

All costs are estimated as per 2014 US Dollars. All $p<0.0001$, Endometriosis vs. Control Cohorts

Fig. 4 Endometriosis-related healthcare costs during 12-month follow-up period. Values over post-period are cumulative cost since index. Values in each time period following index date are cumulative costs since index date

Table 3 Healthcare costs by age during 12-month post-index period

\begin{tabular}{llll}
\hline Outcome & Endometriosis patients & Controls & $p$ value \\
\hline Age 18-29 & $N=16,322$ & $N=123,988$ & \\
Overall healthcare costs, mean (SD) & $\$ 14,369(19,963)$ & $\$ 3649(12,797)$ & $<0.0001$ \\
Pharmacy costs, mean (SD) & $\$ 1646(4004)$ & $\$ 736(3210)$ & $<0.0001$ \\
Age 30-39 & $N=43,441$ & $N=346,037$ & \\
Overall healthcare costs, mean (SD) & $\$ 16,203(20,765)$ & $\$ 4609(16,166)$ & $<0.0001$ \\
Pharmacy costs, mean (SD) & $\$ 1858(4742)$ & $\$ 931(3489)$ & $<0.0001$ \\
Age 40-49 & $N=53,743$ & $N=457,574$ & \\
Overall healthcare costs, mean (SD) & $\$ 17,541(22,122)$ & $\$ 5120(16,435)$ & $<0.0001$ \\
Pharmacy costs, mean (SD) & $\$ 1766(4850)$ & $\$ 1265(4349)$ & $<0.0001$ \\
\hline
\end{tabular}

All costs are estimated as per 2014 US\$

$S D$ standard deviation

absenteeism [23] and provided indirect cost estimates for the USA of about $\$ 3200 /$ year for absenteeism due to endometriosis symptoms and about $\$ 14,800$ for presenteeism (values converted into 2014 US\$). Instead of using records of absence and disability claims, that study based indirect cost estimates on responses by patients to versions of the Work Productivity and Activity Impairment (WPAI:GH) and ShortForm-36 version 2 (SF36v2), and estimated the work loss in terms of lost wages without adjustments for reduced pay for short- and long-term disability.

A previous study characterized the healthcare costs and utilization of endometriosis patients [22]. Although the prior study followed costs and utilization patterns over a longer period of time (up to 5 years for a small percentage of patients), the current analysis expands upon this previous work in several ways: by reporting endometriosis-related costs separately, examining trends within the first 
Table 4 Multivariable analysis of costs per patient during 12-month post-index period

\begin{tabular}{lllll}
\hline Type of cost & $\begin{array}{l}\text { Endometriosis } \\
\text { patients }\end{array}$ & Controls & $\begin{array}{l}\text { Incremental cost } \\
\text { (endometriosis vs. } \\
\text { controls) }\end{array}$ & $\begin{array}{l}\text { Cost ratio }(95 \% \\
\text { confidence interval) }\end{array}$ \\
\hline Total healthcare costs, mean $(\mathrm{SD})$ & $\$ 14,649(\$ 17,675)$ & $\$ 4646(\$ 5606)$ & $\$ 10,002$ & $3.15(3.12-3.18)$ \\
$\quad \begin{array}{l}\text { Indirect costs, mean }(\mathrm{SD})^{\mathrm{a}} \\
\text { Absence costs }\end{array}$ & $\$ 6819(1698)$ & $\$ 4687(\$ 1167)$ & $\$ 2132$ & $1.46(1.38-1.54)$ \\
Short-term disability costs & $\$ 5157(\$ 1312)$ & $\$ 4254(\$ 1082)$ & $\$ 903$ & $1.21(1.16-1.27)$ \\
\hline
\end{tabular}

All costs are estimated as per 2014 US\$

All cohort differences are statistically significant $p<0.001$ (endometriosis vs. control cohorts)

$S D$ standard deviation

${ }^{a}$ Includes absence, short-term disability, and long-term disability data

year post-diagnosis, and by providing multivariate models to provide cost estimates adjusted for variations in baseline covariates. It also contains a somewhat broader sample of patients, including women up to 49 years of age (as opposed to 45 years in Fuldeore et al.'s analysis [22]). Importantly, this study provides an update in an evolving field of treatment, and confirms changes in approaches to gynecological treatment.

A recent analysis shows that hysterectomies and oophorectomies (as treatments across all indications and not just endometriosis) have shown modest decreases in prevalence since the year 2000 with a dramatic shift towards outpatient instead of inpatient procedures [21]. In an analysis spanning the years 2000-2010, Fuldeore et al. [22] reported that $40 \%$ of endometriosis patients received an inpatient admission in their first year. In contrast, in the current analysis spanning the years 2010-2014 only $29 \%$ received an inpatient admission. These numbers include admissions for all reasons, not just endometriosis, but because surgical treatment is very common within the first year of diagnosis $[9,21]$, this is very likely related to a drop in inpatient treatment for endometriosis.

Despite changes in the treatment landscape, surgery remains a mainstay of endometriosis therapy in our analysis, with $38 \%$ of the patients undergoing a hysterectomy in the first year post diagnosis, and two-thirds undergoing a surgical procedure used to treat endometriosis.
This high rate of hysterectomy in the presence of less invasive surgical interventions and pharmacotherapy might represent a diagnostic delay necessitating a more invasive treatment approach; future research should explore this further.

Most newly diagnosed endometriosis patients have incurred pharmacy claims for pain management, and an exceedingly high proportion of our sample of endometriosis patients, nearly $90 \%$, had at least one prescription for opioids. The use of opioids for pain management for endometriosis warrants further investigation.

A notable strength of our study is that it included a large cohort of endometriosis and matched non-endometriosis patients to evaluate the direct and indirect healthcare costs. Additionally, this study provides a current cost trend for endometriosis by using data from a more contemporary time frame than previously available.

This study has several limitations inherent to administrative claims data. As patients were identified and variables were captured through administrative claims data, endometriosis-related symptoms, which are not recorded as a diagnosis on a medical claim, may not have been captured. The diagnosis of endometriosis and clinical characteristics were determined using ICD-9-CM diagnosis or procedure codes, which are subject to data coding limitations and data entry error, and it is possible that women with endometriosis may have inadvertently 
been included in the control group including those with symptoms but for whom a diagnosis had not been made yet or those for whom a diagnosis had not been recorded. The use of over-the-counter medications and other selfmanagement techniques is not usually captured in the claims data, so the use of over-thecounter NSAIDs or other pain management medications is not included in our analysis. The indirect costs included in this study are limited to absenteeism and disability claims by the employee and do not include reduced presenteeism or potential caregiver burden, as well as any other humanistic burden associated with this chronic condition. The absence costs themselves may be conservative, as the disruption of missing workers may result in effectively more work loss than is reflected in each patient's missing hours [24]. Endometriosis may have important effects, such as on the psychological well-being of patients [25-27], that fall outside of the scope of the data used in this analysis. Finally, findings from this observational study may be prone to bias from nonrandom selection into the treatment group and was limited to endometriosis patients covered by Commercial health plans. Therefore, the results are not generalizable to those covered under other types of insurance or who lack coverage.

\section{CONCLUSION}

Patients with endometriosis had significantly higher direct healthcare costs and indirect costs (as measured by absenteeism, short-term disability, and long-term disability) compared to patients without endometriosis in the 12 months follow-up period. Given its prevalence, this suggests a substantial disease burden associated with endometriosis to the individual, healthcare system, and society.

\section{ACKNOWLEDGEMENTS}

Funding. This study and article processing fees (including Open Access fee) were funded by
AbbVie Inc., and conducted by Truven Health Analytics, USA.

Medical Writing Assistance. Editorial/writing assistance for this manuscript was provided by Santosh Tiwari, an employee of Truven Health Analytics. AbbVie funded editorial/writing assistance services.

Authorship. All named authors meet the International Committee of Medical Journal Editors (ICMJE) criteria for authorship for this article, take responsibility for the integrity of the work as a whole, and have given their approval for this version to be published.

Disclosures. Ahmed $\mathrm{M}$ Soliman is an employee of AbbVie Inc. and may own AbbVie stocks/stock options. Jane Castelli-Haley is an employee of AbbVie Inc. and may own AbbVie stocks/stock options. Eric Surrey is medical director at the Colorado Center for Reproductive Medicine, has served in a consulting role on research to AbbVie, and is on the speaker bureau for Ferring Laboratories. Machaon Bonafede is an employee of Truven Health Analytics, an IBM Company. James $\mathrm{K}$ Nelson is an employee of Truven Health Analytics, an IBM Company.

Compliance with Ethics Guidelines. This article does not contain any studies with human participants or animals performed by any of the authors. The research utilized deidentified patient data from administrative claims using codes in compliance with the Health Insurance Portability and Accountability Act (HIPAA) of 1996. Thus, it was exempt from the institutional review board approval.

Data Availability. The datasets generated during and/or analyzed during the current study are not publicly available because of their proprietary nature but are available from the corresponding author on reasonable request.

Open Access. This article is distributed under the terms of the Creative Commons Attribution-NonCommercial 4.0 International License (http://creativecommons.org/licenses/ by-nc/4.0/), which permits any 
noncommercial use, distribution, and reproduction in any medium, provided you give appropriate credit to the original author(s) and the source, provide a link to the Creative Commons license, and indicate if changes were made.

\section{REFERENCES}

1. Burney RO, Giudice LC. Pathogenesis and pathophysiology of endometriosis. Fertil Steril. 2012;98:511-9.

2. Adamson GD, Kennedy S, Hummelshoj L. Creating solutions in endometriosis: global collaboration through the World Endometriosis Research Foundation. J Endometr Pelvic Pain Disord, 2010;2(1): 3-6. http://www.nichd.nih.gov/health/topics/ endometri/Pages/default.aspx. Accessed 12 July 2017.

3. Luciano AA, LaMonica R, Luciano DE. Strategies and steps for the surgical management of endometriosis. OBG Manag. 2011;23:34-50.

4. Juneau biosciences, LLC. End to endo. Genetic endometriosis research study. http://www. endtoendo.com/Endometriosis_Overview_End_to_ Endometriosis.html. Accessed 12 July 2017.

5. Armstrong C. ACOG updates guideline on diagnosis and treatment of endometriosis. Am Fam Phys. 2011;83:84-5.

6. Streuli I, de Ziegler D, Santulli P, et al. An update on the pharmacological management of endometriosis. Expert Opin Pharmacother. 2013;14:291-305.

7. Olive DL, Schwartz LB. Endometriosis. N Engl J Med. 1993;328:1759-69.

8. Bedaiwy MA, Barker NM. Evidence based surgical management of endometriosis. Middle East Fertil Soc J. 2012;17:57-60.

9. Soliman AM, Yang H, Du EX, Kelley C, Winkel C. The direct and indirect costs associated with endometriosis: a systematic literature review. Hum Reprod. 2016;31:712-22.

10. Gao X, YC Y, Outley J, Simon J, Botteman M, Spalding J. Health-related quality of life burden of women with endometriosis: a literature review. Curr Med Res Opin. 2006;22(9):1787-97.

11. Soliman AM, Coyne KS, Zaiser E, Castelli-Haley J, Snabes MC, Surrey ES. The effect of endometriosis symptoms on absenteeism and presenteeism in the workplace and at home. J Manag Care Spec Pharm. 2017;23(7):745-54.

12. Soliman AM, Coyne KS, Gries KS, Castelli-Haley J, Fuldeore MJ. The burden of endometriosis symptoms on health-related quality of life in women in the United States: a cross-sectional study. J Psychosom Obstet Gynaecol. 2017;38:238-48 .

13. Simoens S, Hummelshoj L, D'Hooghe T. Endometriosis cost estimates and methodological perspective. Human Reprod Update. 2007;13:394-404.

14. Simoens S, Dunselman G, Dirksen C, et al. The burden of endometriosis: costs and quality of life of women with endometriosis and treated in referral centers. Hum Reprod. 2012;27:1292-9.

15. Soliman AM, Taylor $\mathrm{H}$, Bonafede $\mathrm{M}$, Nelson JK, Castelli-Haley J. Incremental direct and indirect cost burden attributed to endometriosis surgeries in the United States. Fertil Steril. 2017;107(5):1181-90.

16. United States Department of Labor: bureau of labor statistics. Consumer price index (CPI). https:// www.bls.gov/cpi/. Accessed 12 July 2017.

17. Mullahy J. Much ado about two: reconsidering retransformation and the two-part model in health econometrics. J Health Econ. 1998;17:247-81.

18. Fuldeore $M$, Yang $H$, Soliman AM, Winkel C. Healthcare utilization and costs among women diagnosed with uterine fibroids: a longitudinal evaluation for 5 years pre- and post-diagnosis. Curr Med Res Opin. 2015;31(9):1719-31.

19. Jensen JT, Lefebvre P, Laliberté F, et al. Cost burden and treatment patterns associated with management of heavy menstrual bleeding. J Womens Health (Larchmt). 2012;21(5):539-47.

20. Mirkin D, Murphy-Barron C, Iwasaki K. Actuarial analysis of private payer administrative claims data for women with endometriosis. J Manag Care Pharm. 2007;13:262-72.

21. Fuldeore M, Chwalisz K, Marx S, et al. Surgical procedures and their cost estimates among women with newly diagnosed endometriosis: a US database study. J Med Econ. 2011;14:115-23.

22. Fuldeore M, Yang H, Du EX, Soliman AM, Wu EQ, Winkel C. Healthcare utilization and costs in women diagnosed with endometriosis before and after diagnosis: a longitudinal analysis of claims databases. Fertil Steril. 2015;103:163-71. 
23. Nnoaham KE, Hummelshoj L, Webster P, et al. Impact of endometriosis on quality of life and work productivity: a multicenter study across ten countries. Fertil Steril. 2011;96:366-73.

24. Nicholson S, Pauly MV, Polsky D, et al. Measuring the effects of work loss on productivity with team production. Health Econ. 2006;15:111-23.

25. Facchin F, Barbara G, Saita E, et al. Impact of endometriosis on quality of life and mental health: pelvic pain makes the difference. J Psychosom Obstet Gynaecol. 2015;36(4):135-41.
26. Laganà AS, La Rosa VL, Rapisarda AMC, et al. Anxiety and depression in patients with endometriosis: impact and management challenges. Int J Womens Health. 2017;9:323-30.

27. Vitale SG, La Rosa VL, Rapisarda AMC, Laganà AS. Impact of endometriosis on quality of life and psychological well-being. J Psychosom Obstet Gynaecol. 2017;38(4):317-9. 